\title{
A imagem e seus sentidos imanentes e transcendentes
}

\section{Sílvio Antonio Luiz Anaz}

Doutor; Universidade de São Paulo, São Paulo, SP, Brasil

silvioanaz@usp.br

\section{Resumo}

Este artigo busca contribuir na compreensão da natureza da imagem e de seu papel na geração de sentidos nos processos comunicacionais. Baseada principalmente nas perspectivas teóricas de Durand (2002), Jung (1994, 2011) e Damásio (2004, 2011), a reflexão explora como se dá a construção da imagem simbólica, a partir do papel dos arquétipos e das capacidades de percepção e de imaginação humanas, e de que forma esse tipo de imagem constrói os significados que produz. Como resultado, propõe-se um conceito de imagem que a coloca como elemento básico e essencial do pensamento humano que antecede ontológica e temporalmente a palavra e é dotada de significações imanentes e transcendentes.

\section{Palavras-chave}

Imagem. Simbólico. Arquétipo. Representação. Significado.

\section{Introdução}

Este artigo apresenta uma reflexão sobre a natureza da imagem e seu papel na geração de significações nos processos comunicacionais fundamentada nas proposições de Gilbert Durand (2002) no campo da antropologia, de Carl Gustav Jung (1994, 2011) na psicologia e de Antônio Damásio $(2004,2011)$ na neurociência. Autores que nos levam a pensar a imagem como produto da combinação das capacidades de percepção e de imaginação humanas e a destacar um tipo particular que impacta na geração de sentidos e que surge a partir do processo do imaginário: a imagem simbólica.

$\mathrm{Na}$ perspectiva heurística desenvolvida a seguir, a imagem simbólica deve ser entendida como fruto de um trajeto antropológico assentado entre forças opostas: de um lado, as pulsões subjetivas do ser humano; do outro, em sentido contrário, as coerções dos meios social e natural a que ele está sujeito (DURAND, 2002). Para apreender essa complexa natureza da imagem e o processo pelo qual ela produz os significados que produz, é preciso compreender como ela se origina e os elementos envolvidos em sua constituição. 


\section{Origem e formação das imagens}

A imagem que se forma na nossa mente como representação dos fenômenos no mundo, revelada nas investigações da neurociência (DAMÁSIO, 2004, 2011), deve ser entendida como o resultado de um processo de mapeamento, de uma habilidade cartográfica do cérebro para manter-se informado de todas as coisas externas a ele (como o próprio corpo ao qual pertence e as coisas do mundo, extracorporais). Segundo Damásio (2011), ao criar mapas, o cérebro também cria imagens, sendo a consciência a faculdade que faz o ser experimentar os mapas como imagens, manipulá-las e usar o raciocínio a partir delas. Assim, a imagem constitui-se no principal meio circulante da mente. Nesse sentido, Wunenburger (2018) afirma que

[...] o real só é pensável sob forma de uma imagem porque a consciência reencontra o mundo no ato perceptivo, o mundo não passa de uma totalidade de imagens em potência que se reportam de repente a um centro de percepção: o Self. (BERGSON, $1959^{1}$ apud WUNENBURGER, 2018, p. 59).

Essa primordialidade ontológica e temporal da imagem no pensamento é defendida também, a partir de diferentes perspectivas, nas reflexões de Aristóteles (2006), Bachelard (1997) e Durand (2002), entre outros pensadores.

Damásio (2011) explica o processo de mapeamento e formação das imagens a partir do ato enraizado no cérebro de imitar ou representar aquilo que é externo a ele, ato esse mediado pelos padrões sensoriais existentes no ser (visão, audição, tato, propriocepção etc.):

0 cérebro humano é um imitador inveterado. Tudo o que está fora do cérebro - o corpo propriamente dito, desde a pele até as vísceras obviamente, e mais o mundo circundante, homens, mulheres, crianças, cães e gatos, lugares, tempo quente e frio, texturas lisas e ásperas, sons altos e baixos, mel doce e peixe salgado -, tudo é imitado nas redes cerebrais [...] Em conclusão, as imagens baseiam-se em mudanças que ocorrem no corpo e no cérebro durante a interação física de um objeto com o corpo. Sinais enviados por sensores localizados em todo o corpo constroem padrões neurais que mapeiam a interação do organismo com o objeto. Os padrões neurais são formados transitoriamente nas diversas regiões sensoriais e motoras do cérebro que normalmente recebem sinais provenientes de regiões específicas do corpo. A montagem dos padrões neurais transitórios é feita a partir de uma seleção de circuitos neuronais recrutados pela interação. Podemos conceber esses circuitos neuronais como tijolos

BERGSON, Henri. Matière et mémoire. Paris: PUF, 1959. Apud Wunenburger (2018). 
preexistentes no cérebro para serem usados na construção das imagens. (DAMÁSIO, 2011, doc. não paginado).

Tal representação do mundo dá-se de forma ativa e não passiva, como enfatiza Damásio, à medida que elementos a priori e frutos da experiência, contidos no interior do cérebro, atuam na construção dos mapas e imagens:

Não se trata de mera cópia, de uma transferência passiva do que está fora do cérebro para seu interior. A montagem conjurada pelos sentidos envolve uma contribuição ativa vinda de dentro do cérebro, disponível desde cedo no desenvolvimento, e a ideia de que o cérebro é uma tábula rasa já perdeu a credibilidade há um bom tempo (DAMÁSIO, 2011, doc. não paginado).

A participação indubitável de componentes a priori no mapeamento que leva à formação das imagens, mencionado por Damásio (2011), é afirmada por Pinkler (2004), para quem os experimentos nos campos da psicologia têm demonstrado o papel que as características hereditárias têm no comportamento individual e na construção de representações de mundo - em conformidade com a hipótese de que a herança genética e os componentes ambientais são atuantes, em conjunto, no desenvolvimento do indivíduo, e em contraposição à hipótese da tábula rasa. Pinkler (2004) elenca evidências empíricas e reflexões - da psicologia evolutiva à antropologia, passando pela linguística - de que há uma natureza humana universal e que a mente do sapiens possui uma organização inata, com elementos a priori que atuam na mediação do ser com o mundo, e, portanto, no mapeamento pelo cérebro das coisas externas a ele.

A participação de elementos a priori no ato perceptivo que leva à formação de imagens as quais buscam representar o fenômeno percebido é enfatizada por Wunenburger (2018). Para ele, imagens mnemônicas, relativas a percepções prévias memorizadas, e de antecipação, que expressam o que queremos, desejamos ou esperamos, participam ativamente do ato perceptivo, o que leva o processo cognitivo a um ajuste entre os elementos a priori e o real:

Mesmo preparada e informada por imagens a priori, a imagem perceptiva tem por horizonte a coisa mesma, o que leva a adaptar ao máximo o estado subjetivo ao estado objetivo, em particular pelo viés da atenção dirigida às coisas. (WUNENBURGER, 2018, p. 60, grifo do autor).

Além dos elementos relacionados à memória, há indícios de que outro componente a priori participe da constituição de imagens e de seus significados: o arquétipo. Em hipótese desenvolvida pelo psiquiatra e psicanalista Carl Gustav Jung (2011) e retrabalhada mais 
tarde pelo antropólogo francês Gilbert Durand (2002), a ideia do arquétipo como elemento a priori que atua ativamente na construção das imagens pela mente é essencial na compreensão desse fenômeno e será abordada na próxima seção.

Antes, é preciso destacar que, além das imagens obtidas pela percepção imediata do que é exterior ao cérebro, o Homo sapiens tem também a capacidade única da produção de imagens de coisas que não se apresentam à percepção imediata. As imagens imaginadas são fruto da atuação conjunta da memória, que fornece a matéria-prima, e da imaginação, que opera de forma criadora. Gärdenfors (2006) destaca que as imagens imaginadas não aparecem do nada e são construídas a partir de uma prévia experiência (memória). Uma das capacidades mais recentes da trajetória evolutiva da espécie humana - tendo sido adquirida entre 30 mil e 70 mil anos atrás, devido a mutações genéticas provavelmente ocorridas ao acaso nas conexões internas do cérebro do Homo sapiens (HARARI, 2012) -, a imaginação criadora capacitou o homem a imaginar o que não existe, a criar ficções. Assim, no caso do Homo sapiens, a imagem pode ser tanto fruto de sensações e percepções conectadas com um aqui e agora como produto da capacidade criadora da imaginação, isto é, imagens como representações desconectadas da realidade presente e imediata.

De toda forma, a imagem é, em última instância, sempre mental, sempre representação no mundo interior, psíquico, de algo existente ou não-existente. Sendo sempre mentais, as imagens são totalmente privadas, estando disponíveis diretamente apenas para o "possuidor da mente na qual elas ocorrem" (DAMÁSIO, 2011), sendo impossível que as imagens formadas na mente de um indivíduo sejam observadas por outros indivíduos, que podem, no máximo, supô-las.

As artes e os processos comunicacionais, no entanto, são tentativas dos criadores e possuidores das imagens mentais de compartilhá-las com outros sujeitos. No processo de compartilhamento, a imagem mental passa então à etapa de sua exteriorização, principalmente por meio de sua materialização. A imagem materializada, no entanto, não é capaz de reproduzir com exatidão a imagem mental original, em função de inúmeros fatores que atuam no processo de tradução de uma natureza interna ao ser para outras externas ao ser. Entre esses fatores estão: o próprio caráter evanescente, onírico ou de devaneio da imagem mental, que torna difícil transpô-la a outros meios; o grau de habilidade do seu criador em reproduzi-la ou transcriá-la e os limites dos recursos disponíveis para sua materialização. De qualquer forma, versões da imagem mental original podem vir a ser materializadas em diferentes linguagens e suportes, como o formato icônico, o verbal, o musical ou a combinação entre eles, dos quais as artes plásticas, a literatura, a canção e o cinema são, respectivamente, alguns exemplos. Nesse processo em que há a exteriorização 
das imagens mentais, Contrera e Baitello Júnior (2006) afirmam que há uma passagem das imagens endógenas (interiores ao ser) para as imagens exógenas (exteriores ao ser), sendo ambas "[...] mediadoras de sentidos e enquanto as imagens exógenas veiculam esses sentidos em mensagens inter-pessoais, as endógenas são portadoras de mensagens intrapessoais [...]" (CONTRERA; BAITELLO JÚNIOR, 2006, p. 121).

Como, em última instância, a imagem é sempre representação mental de fenômenos do mundo - representações construídas a partir das capacidades de percepção, memorização e imaginação de ações e coisas -, coisas e ações são, assim, sempre "imagens potenciais" (WUNENBURGER, 2018). Nessa perspectiva fenomenológica, pode-se pensar a imagem como uma existência que está “[...] situada a meio caminho entre a 'coisa' [visão materialista] e a 'representação' [visão idealista]." (BERGSON, 1999, p. 2).

A exteriorização da imagem mental representa sua manifestação no mundo por meio de diferentes suportes, recursos e linguagens, o que a transforma então em um objeto do mundo, que voltará a se tornar imagem na mente de quem o percebe. Assim, o processo de formação da imagem mental, sua exteriorização e sua rementalização é um moto contínuo, no qual múltiplos fatores participam a cada formação e tentativa de reprodução, tradução ou transcriação da imagem. São fatores que impactam no processo comunicacional dos significados que as imagens mentais e as materializadas suscitam, tornando o fenômeno altamente complexo. Tal complexidade comunicacional da imagem é o ponto discutido a seguir.

\section{Sentidos imanentes e transcendentes da imagem}

Sendo a imagem o meio circulante primordial e fundamento do pensamento, é nela que residem os significados primeiros que o ser humano atribui às manifestações dos objetos e das ações no mundo. Seja o mundo interpretado a partir das artes, da mitologia, da religião ou da ciência moderna, isto é, seja ele entendido como lugar de ações ou de coisas, tudo que nele existe é, na perspectiva do Homo sapiens, dotado de significados (PETERSON, 1999).

Cassirer (1965) propõe a tese de que o ato perceptivo no ser humano é dotado de pregnância simbólica, isto é, toda a experiência é impregnada de significados. Nessa perspectiva, qualquer percepção dos fenômenos é já, ela mesma, dotada de sentido, sendo o ato percepcional ato também de produção simbólica imediata pelo ser humano, fruto da capacidade inata de representar as coisas simbolicamente, seja como resultado de uma 
necessidade ou de uma vontade. Sendo forma primordial de representação dos fenômenos, é na imagem mental que a pregnância simbólica se realiza. Assim, as imagens representam e significam o mundo simultaneamente, como resultado de um processo cognitivo imediato que pode envolver as capacidades de percepção, razão, memória e imaginação. Tais significações podem corresponder tanto a uma realidade material e comprovável (perspectiva científica) como a algo ficcional e não comprovável (perspectivas artística, mitológica e religiosa), sendo a imagem normalmente dotada de sentidos múltiplos, isto é, polissêmica.

Os significados de uma imagem podem advir de uma dimensão concreta do objeto ou ação que ela representa, isto é, da utilidade ou finalidade empírica dele, observável e pragmaticamente comprovável. A imagem de uma maçã, por exemplo, carrega o significado de alimento, pois a experiência humana no mundo a identificou como uma substância comestível, dotada da capacidade de nutrir. Mas, há outra dimensão de onde os significados também surgem, uma instância em que a imaginação criadora do Homo sapiens atua de forma prevalente; é uma dimensão em que as manifestações das coisas e ações no mundo são dotadas de significados que transcendem sua realidade material e empírica e adquirem sentidos imaginados e ficcionais. Nesse caso, a mesma imagem da maçã, usada no exemplo anterior, não é mais uma representação (apenas) de um alimento, ela ganha novos significados simbólicos, como: o do amor, atributo de Afrodite e pomo da discórdia, na Grécia Antiga; o da sensualidade, na tentação, pecado e mal contidos no fruto proibido, no episódio da expulsão de Adão e Eva do paraíso na mitologia cristã; e o da juventude eterna, novamente remetendo ao tema da tentação, desta vez relacionado à deusa Idum, na mitologia nórdica (MARTIN, 2012).

Os significados de uma imagem que se originam da experiência empírica ou da função utilitária do objeto ou ação que ela representa operam no que se pode chamar de instância imanente. Já os significados que extrapolam a experiência empírica e são frutos da imaginação operam no que se pode chamar de instância transcendente. É principalmente desse fenômeno de transcendência que surgem os sentidos simbólicos da imagem.

Uma das perspectivas para a compreensão do processo de geração de significações transcendentes por uma imagem vem das hipóteses desenvolvidas pelos estudos conjuntos nos campos do imaginário, da psicologia analítica e da hermenêutica dos símbolos. 0 ponto de partida e um dos principais elementos nesses estudos é a tese proposta pelo psiquiatra e psicanalista suíço Carl Gustav Jung $(1994,2011)$ de que a mente humana é dotada de formas e ideias eternas, universais e herdadas, isto é, de imagens primordiais que ele denominou 
como arquétipos. Jung (2011) propõe o conceito de arquétipo a partir de sua experiência clínica e estudos da mitologia que o levam a identificar, nos relatos dos pacientes e nas imagens recolhidas, padrões básicos e categorias comuns que indicam a existência, no cérebro humano, de imagens primordiais que operam na interpretação do mundo, a priori, isto é, independentemente das experiências pessoais do indivíduo. 0 arquétipo seria uma forma vazia, uma ideia pré-existente e ambivalente (com aspectos positivos e negativos), a ser preenchida por imagens advindas da experiência do sujeito no mundo. Nessa perspectiva, os arquétipos ordenam a vida psíquica do sujeito.

O conceito junguiano de arquétipo é retomado por Gilbert Durand (2002) em seus estudos sobre o imaginário e as imagens. Durand (2002) revê a ideia junguiana de arquétipos como a camada mais profunda do inconsciente e como resultado de caminhos virtuais herdados. 0 antropólogo francês vai estabelecer os arquétipos como produtos de estruturas e esquemas biopsíquicos - associados a características fisiológicas e psicológicas do Homo sapiens - que operam não na base, mas sim em uma mediação entre as pulsões do ser humano e as coerções do mundo externo (social e natural), dentro daquilo que ele definiu como trajeto antropológico, que nada mais é do que o imaginário, processo do qual surgirão as imagens simbólicas ou arquetípicas, dotadas de sentidos que ultrapassam a sua natureza, uma vez que são imagens que preenchem os arquétipos. Ao se tornar arquetípica, a imagem assume sentidos que são transcendentes em relação à natureza (imanência) daquilo de que ela é uma representação.

Para ilustrar esse processo, pode-se tomar como exemplo uma das imagens mais conhecidas sobre o ataque terrorista ao World Trade Center, em Nova York, ocorrido em 11 de setembro de 2001 (Figura 1). Na fotografia, publicada originalmente pela revista norteamericana Time, vê-se um homem de ponta cabeça em queda, com o edifício que foi alvo do atentado ao fundo. Na instância imanente, a imagem denota o salto trágico, o suicídio, a atitude de desespero do ser ante a inevitabilidade da morte. No âmbito simbólico, no entanto, a imagem traz significados que vão além desses significados que ampliam o real e revelam outros elementos não evidenciados no fato em si. 
Figura 1 - Imagem de homem em queda após saltar do World Trade Center, em Nova York (EUA), em decorrência do atentado terrorista de 11 de setembro de 2001

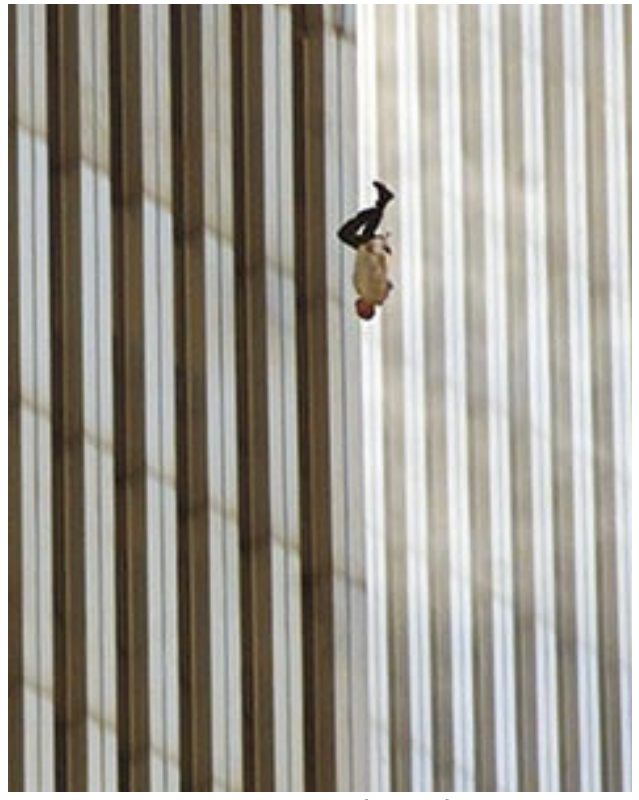

Fonte: Drew (2001)

Tomada a arquetipologia durandiana como referência, pode-se afirmar que se destacam, na imagem (Figura 1), as oposições arquetípicas ascensão vs. queda e puro vs. manchado. Uma perspectiva simbólica que emerge dessa imagem, a partir do contexto histórico em que ela se insere, é a da queda do Ocidente e seus valores. A ideia da queda transcende, assim, a do indivíduo-suicida e constitui-se como metáfora da queda da civilização ocidental, representada no indivíduo em queda e no alto edifício ao fundo, símbolo do poder econômico global dos Estados Unidos, que ruirá em seguida, ante a barbárie (em um ponto de vista) ou ante o heroísmo (no ponto de vista oposto) do ato terrorista. Por deslizamento, emerge também o sentido da oposição arquetípica puromanchado, tendo, mais uma vez, de um lado, os valores seculares e profanos predominantes na sociedade ocidental, e, do outro, os valores religiosos e a ideia do sagrado, predominantes nas sociedades islâmicas de onde vieram os terroristas. Ambas as oposições arquetípicas ascensão vs. queda e puro vs. manchado - são regidas pela lógica do combate e da separação entre as partes. Pode-se, dessa forma, afirmar que tal imagem (Figura 1) se torna arquetípica ou simbólica por representar significados contidos nos arquétipos ascensão vs. queda e puro vs. manchado, significados esses que transcendem o sentido imanente do fenômeno (suicídio) representado na imagem.

A imagem, nesse caso, atualiza os arquétipos, que são primordiais, universais e atemporais, a uma contextualização histórica e social específica e, em sentido oposto, um fato histórico-social específico alcança significados universais, atemporais e primordiais ao 
preencher os arquétipos, ao se tornar simbólico. A imagem que constitui significados que transcendem o sentido real ou empírico daquilo que ela representa é, assim, produto de imaginários, individuais e coletivos, que compartilham arquétipos, estereótipos, símbolos e narrativas míticas que trazem os significados aos quais ela remete.

Há situações, no entanto, em que o significado imanente de uma imagem pode paradoxalmente trazer nele sentidos transcendentes, isto é, seus sentidos imanentes não se limitarão ao seu valor utilitário, empírico, real, mas incluirão significados imaginados, que se supõem frutos de uma revelação. Isso porque a capacidade imaginativa, especialmente nos devaneios e sonhos, e a ação dos arquétipos na interpretação ativa do mundo leva também, nos casos de epifanias, teofanias ou hierofanias, ao estabelecimento de significados imanentes a uma imagem que não dizem respeito estritamente à natureza da coisa representada. Essa situação fica clara nas hierofanias, que Eliade (1992) define como manifestações do sagrado em oposição ao profano.

\begin{abstract}
A partir da mais elementar hierofania - por exemplo, a manifestação do sagrado num objeto qualquer, uma pedra ou uma árvore - e até a hierofania suprema, que é, para um cristão, a encarnação de Deus em Jesus Cristo, não existe solução de continuidade. Encontramo-nos diante do mesmo ato misterioso: a manifestação de algo "de ordem diferente" - de uma realidade que não pertence ao nosso mundo - em objetos que fazem parte integrante do nosso mundo "natural", "profano". (ELIADE, 1992, p. 13).
\end{abstract}

Nesses casos, para Eliade (1992), o objeto continua a ser ele mesmo - isto é, com um valor empírico, natural e, portanto, profano - e torna-se, ao mesmo tempo, outra coisa, de realidade sobrenatural, sagrada. As imagens arquetípicas das montanhas exemplificam esse fenômeno. A imaginação tem dado a esse acidente geográfico atributos arquetípicos relativos à divindade. Alguns dos exemplos disso são: o Monte Olimpo, na Grécia, visto como lar dos deuses na mitologia grega; o monte Fuji (Figura 2), no Japão, entrada ao mesmo tempo do Paraíso do Buda Amida e da abertura vulcânica (hito-ana) que leva ao inferno; e as Quatro Montanhas Sagradas das Quatro Direções habitada pela pátria indígena dos Navajos, na América do Norte (MARTIN, 2012). 
Figura 2 - Imagem artística de representação de uma montanha como manifestação do sagrado na obra Mandala da peregrinação ao monte Fuji, de Kano Motonubu (1476-1559), rolo pendente, Japão

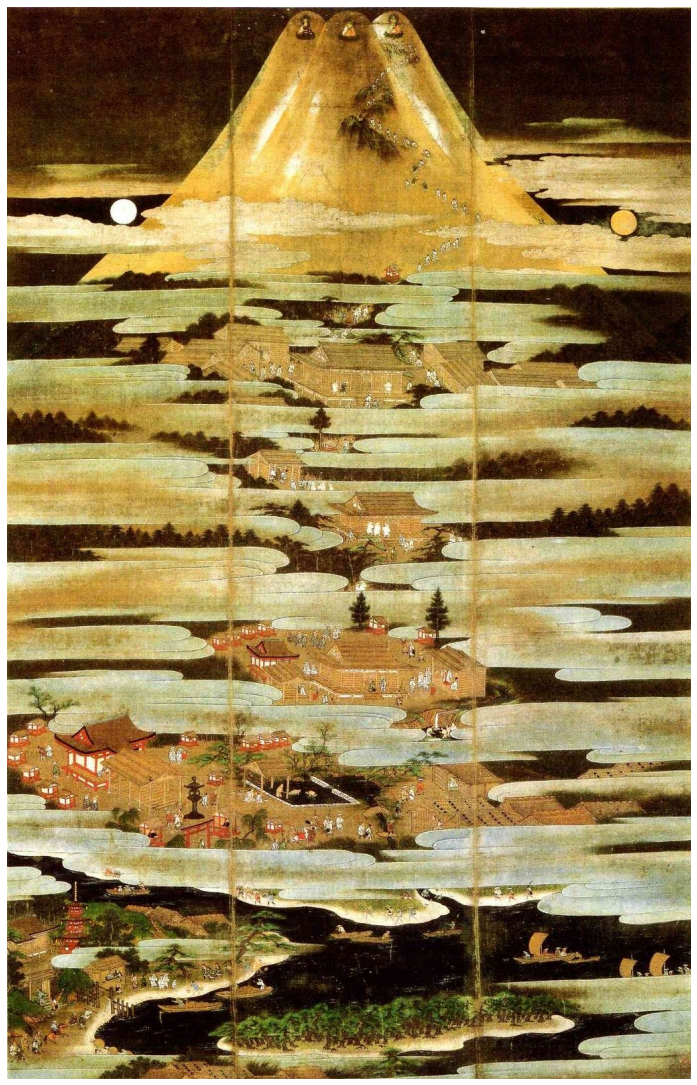

Fonte: Martin (2012, p. 109).

Produto do imaginário, a imagem pode adquirir significações contidas nos arquétipos que ela preenche. Assim, a imagem não traz nela somente sua significação literal, fruto de sua natureza, mas incorpora sentidos oriundos da imaginação, tornando-se simbólica ou arquetípica. Para Wunenburger (2018), a força psíquica e a consistência semântica da imagem simbólica vêm de suas “[...] metassignificações que são, de uma só vez, ligadas ao conteúdo e desligadas porque pertencem a um outro nível de experiência sensível ou inteligível [...]"(WUNENBURGER, 2018, p. 62).

\section{Conclusões}

Pode-se definir, de forma sintética, a imagem como a representação mental da manifestação de objetos e ações no mundo (fenômenos), dotada de significados que são imanentes e transcendentes ao fenômeno representado. No Homo sapiens, a imagem mental corresponde a padrões neurais formados a partir das capacidades de mapear os fenômenos - por meio das percepções sensoriais (visão, audição, olfato, paladar, tato, vestibular, propriocepção etc) - memorizá-los e imaginá-los. Tais habilidades possibilitam ao ser 
humano atribuir significados imanentes ao fenômeno representado pela imagem, assim como atribuir-lhe significados simbólicos ou transcendentes, que o suplementam, ampliam ou revelam elementos incompreendidos nele. Nesse aspecto, seus significados surgem imediatamente dos atos percepcional e imaginativo do ser humano, em função da pregnância simbólica (CASSIRER, 1965).

A hipótese aqui explorada foi a de que o processo de atribuição de significações às imagens se dá a partir da combinação das percepções sensoriais, dos elementos que a priori compõem a mente (arquétipos) e daqueles frutos da experiência do ser no mundo (memória), sendo eles participantes ativos do processo de formação da imagem mentalmente e de seus significados. Assim, a imagem só se constitui como tal na mente do indivíduo que observa o mundo e/ou que imagina as coisas e é, assim, em última instância, sempre uma imagem endógena. No caso do Homo sapiens, a imagem forma-se em uma mente dotada de consciência, subjetividade e self e como fruto do processo do imaginário. Quando exteriorizada e materializada, a imagem torna-se um objeto do mundo que se transforma novamente em imagem na mente dos indivíduos que a percebem. Assim, as imagens mentais são compartilhadas por seu detentor a partir de sua exteriorização e materialização em diferentes linguagens e formatos (icônico, verbal, musical, etc.), constituindo os fundamentos estéticos de imaginários artísticos, políticos e sociais.

Os significados que a imagem traz consigo podem operar em duas instâncias: na instância imanente, com uma perspectiva concreta, utilitária, materialista, de relação direta com a realidade, predominantemente empírica e geradora de sentidos denotativos; e na instância transcendente, com uma perspectiva simbólica, abstrata, que pode ser desconectada da realidade, ficcional, predominantemente a priori, dotada de sentidos conotativos.

A instância transcendente é possível graças à capacidade única do sapiens de imaginar e conhecer simbolicamente. A imaginação, a mais recente habilidade cognitiva surgida no ser humano ao longo da evolução da espécie, permite a criação e a produção simbólica que dá ao Homo sapiens a possibilidade de estabelecer significados às coisas do mundo, inclusive significados que ultrapassam as significações implícitas nas próprias coisas (e fruto das experiências humanas com elas), e criar coisas que não existem no mundo natural, sendo que tais significações buscam dar sentido ao mundo e à existência.

A produção mental da imagem e de seus significados dá-se a partir de múltiplos fatores que podem atuar concomitantemente. Os principais são: as coisas do mundo, externas ao cérebro, que se constituem em material a ser mapeado por ele; os fatores a priori que compõem a mente humana, como as características psicológicas herdadas 
(PINKLER, 2004) e o inconsciente genômico (DAMÁSIO, 2011), que atuam nas predisposições do indivíduo, e os arquétipos (JUNG, 2011; DURAND, 2002), que atuam na formação e significação das imagens; a memória, que armazena imagens do passado e presentifica-as quando acionada com o auxílio da imaginação formal; e a imaginação criadora (BACHELARD, 1997), que possibilita a formação de imagens arquetípicas e das ficções.

É da complexa e ininterrupta combinação desses fatores que o ser humano produz imagens e seus significados. A partir delas, interpreta o mundo, reproduz as imagens e cria novas, que formam os sistemas simbólicos, como a ciência, a arte, a religião e a mitologia, e materializam-se de diferentes formas, como nas imagens icônica, verbal e musical, entre outras, para voltarem a ser reinterpretadas em um contínuo e complexo ciclo comunicacional de novas imagens mentais e materializadas.

\section{Referências}

ARISTÓTELES. De Anima: livros I, II e III. São Paulo: Editora 34, 2006.

BACHELARD, Gastón. A água e os sonhos. São Paulo: Martins Fontes, 1997.

BERGSON, Henri. Matéria e memória: ensaio sobre a relação do corpo com o espírito. São Paulo: Martins Fontes, 1999.

CASSIRER, Ernst. The phiosophy of simbolic forms: the phenomenology of knowledge. New Haven: Yale University Press, 1965. v. 3.

CONTRERA, Malena; BAITELLO JÚNIOR, Norval. Na selva das imagens: algumas contribuições para uma teoria da imagem na esfera das ciências da comunicação. Significação, São Paulo, v. 33, n. 25, p. 113-126, 2006.

DAMÁSIO, António. Em busca de Espinosa. São Paulo: Companhia das Letras, 2004.

DAMÁSIO, António. E o cérebro criou o homem. São Paulo: Companhia das Letras, 2011.

DREW, Richard. Falling Man. 2001. 1 fotografia. Disponível em:

http://100photos.time.com/photos/richard-drew-falling-man. Acesso em: 21 nov. 2018.

DURAND, Gilbert. As estruturas antropológicas do imaginário. São Paulo: Martins Fontes, 2002.

ELIADE, Mircea. O sagrado e o profano. São Paulo: Martins Fontes, 1992.

GÄRDENFORS, Peter. How Homo became sapiens: on the evolution of thinking. Oxford: Oxford University Press, 2006. 
HARARI, Yuval. Sapiens: uma breve história da humanidade. Porto Alegre: L\&PM 2012.

JUNG, Carl Gustav. 0 eu e o inconsciente. Petrópolis: Vozes, 1994.

JUNG, Carl Gustav. Os arquétipos e o inconsciente coletivo. Petrópolis: Vozes, 2011.

MARTIN, Katleen (ed.). 0 livro dos símbolos: reflexões sobre imagens arquetípicas. Colônia: Taschen, 2012.

PETERSON, Jordan. Maps of meanings: the architecture of belief. Nova York: Routledge, 1999.

PINKLER, Steven. Tábula rasa. São Paulo: Companhia das Letras, 2004.

WUNENBURGER, Jean-Jacques. A árvore de imagens. Intexto, Porto Alegre, n. 41, p. 58-69, jan./abr. 2018.

\title{
The image and its immanent and transcendent meanings
}

\begin{abstract}
This paper seeks to contribute to the comprehension of the image's nature and its role in the generation of meanings in communicational processes. Based on theories from Durand (2002), Jung (1994, 2011), and Damásio (2004, 2011), this reflection explores how symbolic images are built - from the role of archetypes and human beings' capacities of imagination and perception - and how this type of image constructs the meanings that it produces. As a result, we propose a concept of image as a basic and essential element in human thoughts that precedes ontologically and temporally the word and produces immanent and transcendent meanings.
\end{abstract}

\section{Keywords}

Image. Symbolic. Archetype. Representation. Meaning. 